\title{
Efficiency of Women's Technical Institutions By Using Bce Model Through Dea Approach
}

\author{
Dr.R.P.Sreedevi ${ }^{1}$, Dr.K.Pushpanjali ${ }^{2}$ \\ ${ }^{1}$ Mathematics, GuruNanak Institutions Of Technical Campus. JNTU, India \\ ${ }^{2}$ Statistics, S.K.University, Anantapur, India
}

\begin{abstract}
This paper conducts an application of the DEA Methodology in the assessment of the performance of JNTUH Colleges the indicators included the Faculty, Students, Infrastructure and Placements of the technical Institutions. The results reveal those institutions that more efficiently carry out these activities. The proposed method has been used for selection of quality attributes in technical education setting the performance of an institute is likely to be influenced by quality of teacher, quality of students, infrastructure administration, extent of training and placement and many others. It is felt that quality and performance evaluation is necessary not only for appraisal but it is also required to improve overall service quality. Finally we discuss about the existence of differences in the strengths and weaknesses between the technical institutions.
\end{abstract}

Key Words: BCC Model, Data Envelopment Analysis, Efficiency Measurement Returns to Scale

\section{Introduction}

The scrutiny upon the government has demanded public entities to increase the efficiency in using the resources they manage. More over, there has also been a greater autonomy of the governmental units resulted from the decentralization processes that recently took place in a number of different countries. These changes called for the use of new management techniques able to value the performance of these units and to provide tools that can con tribute to the improvement of decision-making process in the public sphere. Decreasing effectiveness of the potential indicators able to represent the general efficiency of the entity is due to two linked. One is that each group of indicators evaluates an aspect different from the activity. The other is that different kinds of stake holders will be interested in different aspects of its management.

Therefore in situations in which each input and output can be added in a significant index of productive efficiency, it is useful the application of the Data Envelopment Analysis model (DEA) as an added measure of the relative efficiency of a group of homogeneous Decision Making Units (DMU). I-Huei Ho et al. (2001) investigated the management and performance of engineering educational systems. The study established performance evaluation model for engineering educational systems. The concept of balanced scorecard was explored to construct a performance evaluation model. Ana Lúcia Miranda Lopes and Edgar August Lanzer (2002) addressed the issue of performance evaluation-productivity and quality-of academic departments at a University. Data Envelopment Analysis (DEA) was applied to simulate a process of cross evaluation between the departments. Emilio Martin (2003) applied DEA methodology for assessing the performance of Zaragoza University's departments (Spain). The indicators that were included in the study concerned both the teaching and the research activity of the departments. The results thereof revealed those departments that are more efficiently carrying out these activities. Finally the author discussed about the existence of differences in the strengths and weakness between departments of different areas. John Ruggiero (2004) highlighted that in DEA with nondiscretionary inputs ignores the possibility of correlation among efficiency and the nondiscretionary factors. Hahn-Ming Lee et al. (2005) reported a novel personalized recommendation system with online preference analysis in a distance learning environment called Course bot. Users can both browse and search for course materials by using the interface of Course bot. Kosmas Kotivas et al. (2005) presented a self evaluation methodology on a specific post graduate engineering course in the critical technological area of advanced materials. The methodology developed was based on total quality management (TQM) procedures that were introduced in the higher education sector in Greece. P.Kousalya et al. (2006) applied Analytical Hierarchy Process (AHP) to a decision making problem related to an educational arena.Through survey on the expertoptions, the criteria that cause student absenteeism were identified and the criteriahierarchy was developed. The relative importance of those criteria for Indian environment was obtained through the opinion survey. Cai Yonghong and Lin Chongde(2006) suggested that teacher performance evaluation should find its theoretical foundation in teacher performance constructs. After making literature review, critical case study, critical interview and qualitative research, the authors proposed a new conceptual construct of teacher performance and made necessary analysis for the construct of reliability and validity in empirical approaches. Salah-Ud-Din Khan et al.(2006) developed a reliable instrument to evaluate the performance of Directors of Physical Education working in Government colleges of North West Frontier Province.S. S. Mahapatra and M. S. 
Khan (2007) developed a quality measuring instrument called Edu QUAL and proposed a Neural Network (NN) based integrated approach for evaluating service quality in education sector.

This paper describes the use of DEA methodology to assess the performance of 10 Women's technical institutions with in the JNTU Hyderabad according to the data. In first instance we will select those variables that more accurately describe the consume of resources and the activity carried by the Technical institutions. The results of the analysis will determine comparatively efficient DMUs intending to identify the causes because of which the other DMUs are inefficient.

\section{Data Envelopment Analysis}

Data Envelopment Analysis is a relatively new "data oriented" approach for evaluating the performance of a set of peer entities called Decision Making Units (DMUS) which convert multiple inputs into multiple outputs. The definition of a DMU is generic and flexible. Recent years have seen a great variety of application of DEA for use in evaluation the performances of many different kinds of entities engaged in many different activities in many different contexts in many different countries. These DEA applications have used DMUS of various forms to evaluate the performance of entities, such as hospitals, US Air force wings, Universities, Cities and Courts, business firms, and others, including the performance of countries, regions etc. Because it requires very few assumptions, DEA has also opened up possibilities for use in cases which have been resistant to other approaches because of the complex (often un known ) nature of the relations between the multiple inputs and multiple outputs involved in DMUS.

As pointed out in Cooper, Seiford and Tone (2000), DEA has also been used to supply new insights into activities (and entities ) that have previously been evaluated by other methods. DEA studies of the efficiency of different legal organization forms such as "stock" vs "mutual" insurance companies have shown that previous studies have fallen short in their attempt to evaluate the potentials of these different forms of organizations. Similarly a use of DEA has suggested reconsideration of previous studies of the efficiency with which pre and post merger activities have been conducted in banks that were studied by DEA.

Since DEA in its present form was first introduced in 1978, researchers in a number of fields have quickly recognized that it is an excellent and easily used methodology for modeling operational process for performance evaluation. This has been accomplished by other developments. For instance, ZHU (2002) provides performance evaluation and benchmarking. DEA'S empirical orientation and the absence of a need for the numerous a prior assumption.

For instance, consider what one wants to mean by "efficiency" or more generally, what one wants to mean by saying that one DMU is more efficient than another DMU. This is accomplished in a straight forward manner by DEA without requiring explicitly formulated assumption and variation with various types of models such as linear and non- linear regression models.

\section{Bcc Model}

One limitation of the CCR model is its assumption of Constant Returns to Scale (CRS). This over restrictive assumption might have been a reason for DEA not being applied extensively in the initial years. Banker Charnes and Cooper (1984) developed a simple but ingenious modification to the CCR DEA model, which is to be referred to henceforth as the BCC model, to handle variable returns to scale (VRS). A separation into technical and scale efficiencies is accomplished by the methods developed without altering the latter conditions for use of DEA directly on observational data. Technical inefficiencies are identified with failures to achieve best possible output levels and/or excessive amounts of inputs. Banker et al. introduce a new separate variable, which makes it possible to determine whether operations were conducted in regions of increasing, constant or decreasing returns to scale in multiple input and multiple output situations.

Throughout this we confine attention to technical aspects of efficiency so that no price or cost data are required. Suppose, therefore that we have $n$ DMUS (decision making units) where each $D M U j, j=1,2 \ldots n$ produces the $\mathrm{s}$ outputs in different amounts, Yrj $\mathrm{r}=1,2, \ldots \mathrm{s}$, using the same $\mathrm{m}$ inputs $\mathrm{Xij} \mathrm{i}=1,2 \ldots \mathrm{m}$ also in different amounts.

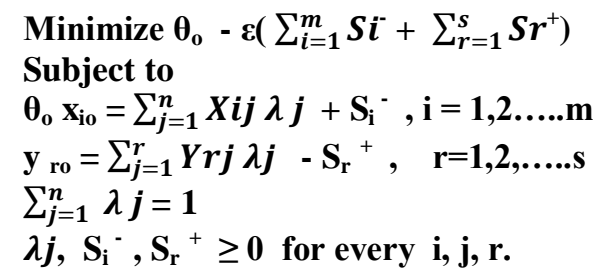

Any real number $n>0$, there exists another number $n / 2$ such that $n>n / 2>0$. see Arnold et al.(1998) for further discussion of non-Archimedean constructs and their uses in DEA. It is not necessary to specify a value for $\varepsilon$ since it can be implemented in the following two stage manner:

In stage 1 a value of $\min \boldsymbol{\theta}_{\mathbf{o}}=\boldsymbol{\theta}_{\mathbf{0}} *$ is secured for (1) modified so that slacks are not included in the objective. 
In stage 2 then maximizes the sum of the slacks with the $\boldsymbol{\theta}_{\mathbf{0}}$ constraint fixed at $\boldsymbol{\theta}_{\mathbf{0}}=\boldsymbol{\theta}_{\mathbf{0}}$ *

\section{Returns to Scale}

The above efficiency measures are based on Variable Returns to Scale technology (VRS). The variable returns to scale result in a non- proportionate change (increase or decrease) in the outputs. The three types of returns to scale and the difference between the input-reducing and the output-increasing measures are illustrated on figures.

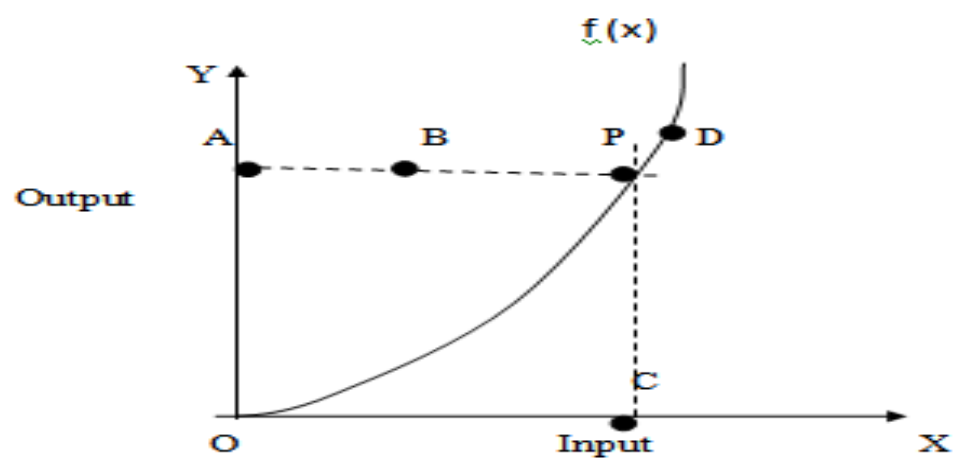

INCREASING RETURNSTO SCALE

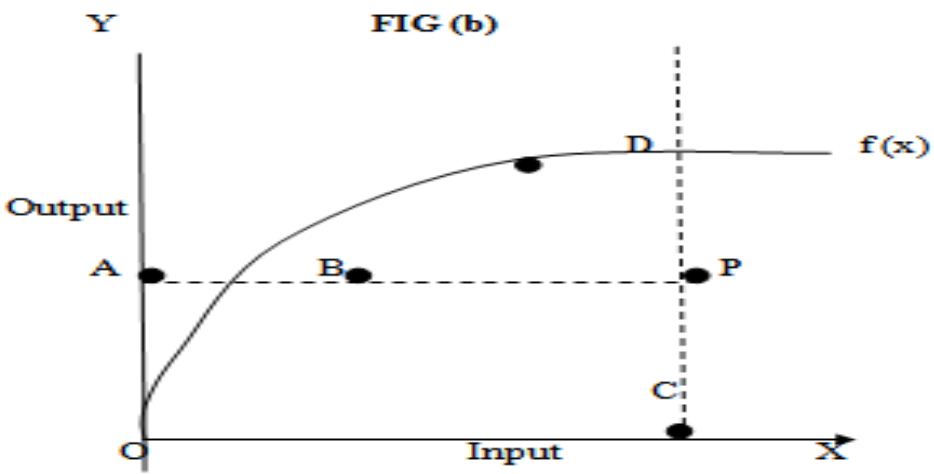

DECREASING RETURNS TO SCALE

In fig (a) represents a function with an increasing slope. For every unit increase in the input, the output increases by a more than proportionate quantity displaying increasing returns to scale(IRS).

In fig (b) represents decreasing returns to scale (DRS) where the function has a slope that decreases as the input increases. $\mathrm{P}$ is a firm that lies below the efficient frontier.

In each of the three cases, $\mathrm{P}$ could be projected onto the frontier either under an input- reducing consideration or an output - increasing consideration. B and D are projected points on the frontier obtained for comparison. The input-reducing efficiency measure is given by $\mathrm{CP} / \mathrm{CD}$.

In the case of CRS as in fig (a), the triangles $\Delta \mathrm{OAB}$ and $\Delta \mathrm{DCO}$ are similar. By the law of similar triangles

$\frac{A B}{C D}=\frac{O A}{C D}$

$\frac{A B}{A P}=\frac{C P}{C D}$

V. Empirical Investigation

10 Women's Technical Institutions under JNTU Hyderabad have been selected for collection of data. All the 10 colleges are exposed to a common frontier. The overall technical efficiency measured by variable returns to scale is calculated to each of the technical institutions. 


\section{Table: Statistic by BCC Model}

\begin{tabular}{|l|l|l|}
\hline Result of analysis & \multicolumn{2}{|l|}{ BCC Score } \\
& & Women's \\
\hline No. of efficient institutions & 8 \\
\hline No. of inefficient institutions & 2 \\
\hline Average efficiency result & \\
\cline { 1 - 1 } Standard deviation & 0.97330 \\
\hline Maximum efficiency result & 0.056301 \\
\hline Minimum efficiency result & 1 \\
\hline & & 0.769 \\
\hline
\end{tabular}

\section{Summary and Conclusions}

A technique has been presented which employs Data Envelopment Analysis to select the most desirable institutions from a list of the technical institutions, within the context of this analysis and assumptions, it is shown that of these 10 institutions evaluated, 5 women's institutions are found to be "near efficient". One of the advantages of using DEA is that for the DEA efficient. In other words, DEA can inform the decision-maker which alter5natives are consistently the best when several attributes are considered, but it also provides information as to how much improvement is needed for each alternative to with respect to inputs and outputs.

The impetus for this research is not necessarily to assist the investor in choosing the best institution. The motivation for this analysis is to show how Data Envelopment Analysis can be used to assist with the multicriteria problem of selecting which institution is preferable. The technique can provide a single composite score for each alternative, which has simplifying value.

\section{References}

[1] I-Huei Ho, Tzai-Fu Cheng and Chieh-Yu Lin, (2001), "The Construction of the Performance Evaluation Model for Engineering Education Systems", International Conference on Engineering Education, August 6-10, Oslo, Norway.

[2] Ana Lúcia Miranda Lopes and Edgar Augusto Lanzer, (2002), "Data Envelopment Analysis-DEA and Fuzzy Sets to Assess the Performance of an Academic Departments: A Case Study at a Federal University of Santa Catarina-UFSC", Pesquisa Operacional,Volume 22, Number 2, pp. 217-230.13

[3] Emilio Martin, (2003), "An Application of the Data Envelopment Analysis Methodology in the Performance Assessment of the Zaragoza University Departments", Documento deTrabajo 2003-06.

[4] John Ruggiero, (2004), "Performance Evaluation When Non-Discretionary Factors Correlate with Technical Efficiency", European Journal of Operations Research, Volume159, pp. 250-257.

[5] Hahn-Ming Lee, Chi-Chun Huang and Tzu-Ting Kao, (2005), "Personalized Course Navigation Based on Grey Relational Analysis", Applied Intelligence, Volume 22, pp.83-92.

[6] Kosmas Kotivas, Maria L. Tsipa and Dimitrios N. Tsipas, (2005), "The Development and Implementation of a Pilot Internal Evaluation Procedure for Postgraduate Engineering Courses”, World Transactions on Engineering \& Technical Education, Volume 4, Number 1, pp. 83-86.

[7] P. Kousalya, V. Ravindranath and K. Vizayakumar, (2006), "Student Absenteeism in Engineering Colleges: Evaluation of Alternatives Using AHP”, Journal of Applied Mathematics and Decision Sciences, Volume 2006, Article ID 58232, pp. 1-26.

[8] Salah-Ud-Din Khan, Mearaj-Ud-Din and Muhammad Shah, (2006), "Development of aReliable and Valid Instrument for the Evaluation of Performance of Directors of Physical Education", Gomal University Journal of Research, Volume 22, pp. 29-26.

[9] Cai Yonghong and Lin Chongde, (2006), "Theory and Practice on Teacher Performance Evaluation", Front. Education China, Volume 1, pp. 29-39.

[10] Mary Caroline N. Castano and Emilyn Cabanda, (2007), "Sources of Efficiency and Productivity Growth in the Philippine State Universities and Colleges: A Non-Parametric Approach", International Business and Economics Research Journal, Volume 6, Number 6, pp. 79-90.

[11] Nina Begičević, Blaženka Divjak and Tihomir Hunjak, (2007), "Development of AHP Based Model for Decision Making on ELearning Implementation", Journal of Information and Organizational Sciences, Volume 31, Number 1, pp. 13-24.

[12] S. S. Mahapatra and M. S. Khan, (2007), "A Neural Network Approach for Assessing Quality in Technical Education: An Empirical Study”, International Journal of Productivity and Quality Management, Volume 2, Number 3, pp. 287-306.

[13] Subhajyoti Ray, (2007), "Selecting a Doctoral Dissertation Supervisor: Analytical Hierarchy Approach to the Multiple Criteria Problem", International Journal of Doctoral Studies, Volume 2, pp. 23-32. 